\title{
Detection and Site Localization of Phosphorylcholine- Modified Peptides by NanoLC-ESI-MS/MS Using Precursor Ion Scanning and Multiple Reaction Monitoring Experiments
}

\author{
Thomas Timm, ${ }^{1}$ Christof Lenz, ${ }^{2,6}$ Dietrich Merkel, ${ }^{3}$ Christian Sadiffo, ${ }^{1}$ Julia Grabitzki, ${ }^{4}$ \\ Jochen Klein, ${ }^{5}$ Guenter Lochnit ${ }^{1}$
}

${ }^{1}$ Protein Analytics, Institute of Biochemistry, Faculty of Medicine, Justus-Liebig-University Giessen, 35392, Giessen, Germany

${ }^{2}$ Bioanalytical Mass Spectrometry Group, Max Planck Institute for Biophysical Chemistry, 37077, Göttingen, Germany

${ }^{3}$ AB Sciex Germany GmbH, 64293, Darmstadt, Germany

${ }^{4}$ ScheBo Biotech AG, 35394, Giessen, Germany

${ }^{5}$ Department of Pharmacology, Goethe University College of Pharmacy, 60438, Frankfurt, Germany

${ }^{6}$ Institute of Clinical Chemistry, University Medical Center, 37075, Göttingen, Germany

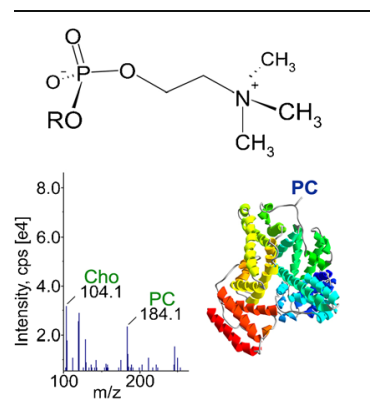

Abstract. Phosphorylcholine (PC)-modified biomolecules like lipopolysaccharides, glycosphingolipids, and (glyco)proteins are widespread, highly relevant antigens of parasites, since this small hapten shows potent immunomodulatory capacity, which allows the establishment of long-lasting infections of the host. Especially for PCmodified proteins, structural data is rare because of the zwitterionic nature of the PC substituent, resulting in low sensitivities and unusual but characteristic fragmentation patterns. We have developed a targeted mass spectrometric approach using hybrid triple quadrupole/linear ion trap (QTRAP) mass spectrometry coupled to nanoflow chromatography for the sensitive detection of PC-modified peptides from complex proteolytic digests, and the localization of the PC-modification within the peptide backbone. In a first step, proteolytic digests are screened using precursor ion scanning for the marker ions of choline $(\mathrm{m} / \mathrm{z} 104.1)$ and phosphorylcholine $(\mathrm{m} / \mathrm{z} 184.1)$ to establish the presence of PC-modified peptides. Potential PC-modified precursors are then subjected to a second analysis using multiple reaction monitoring (MRM)-triggered product ion spectra for the identification and site localization of the modified peptides. The approach was first established using synthetic PC-modified synthetic peptides and PC-modified model digests. Following the optimization of key parameters, we then successfully applied the method to the detection of PCpeptides in the background of a proteolytic digest of a whole proteome. This methodological invention will greatly facilitate the detection of PC-substituted biomolecules and their structural analysis.

Keywords: Phosphorylcholine, Post-translational modification, ESI-MS/MS, Precursor ion Scanning, Multiple reaction monitoring, Immunomodulation

Received: 26 August 2014/Revised: 17 October 2014/Accepted: 22 October 2014/Published Online: 9 December 2014

\section{Introduction}

$\mathrm{P}^{\mathrm{h}}$ hosphorylcholine (PC) has been recognized as a structural component in both prokaryotic and eukaryotic pathogens. First detected in the Gram-positive bacterium Streptococcus pneumoniae in 1967, it was later found in Gram-negative bacteria and many important disease-causing parasites, such as protozoa as well as gastrointestinal and filarial nematodes [1,

Correspondence to: Guenter Lochnit; e-mail: guenter.lochnit@biochemie.med.unigiessen.de
2]. PC modifications have been observed on teichoic acid, lipoteichoic acid, lipopolysaccharides, glycolipids, and glycoproteins [3-6]. There is first evidence that PC-substituted peptides may occur also in mammals (e.g., on placental secretory polypeptides) $[7,8]$.

PC-bearing antigens have been found to possess immunomodulatory capacity and to interfere with key proliferative signaling pathways in B- and T-cells as well as in dendritic and mast cells, thus facilitating the survival of parasites within their hosts [1, 916]. Therefore, these effects could contribute to the observed low antibody levels and poor lymphocyte responsiveness. Detailed 
data on the different types of PC-carrying compounds as well as on their biosynthesis, however, are limited and have only been reported in the last few years [1, 17-19].

For the characterization of the biological function of PCsubstituted parasitic antigens, the detailed knowledge of their PC-epitope structures is a prerequisite. So far, mass spectrometric analyses have focused on PC-substituted glycosphingolipids and glycans. PC-conjugated glycosphingolipids have been found in all parasitic and free-living nematodes investigated so far [20-24]. PC-substituted glycosphingolipids show characteristic fragmentation patterns in MALDI-TOF-MS and nano-spray ESI-IT-MS because of the loss of a trimethylamine group by Hoffmann elimination and formation of cyclic phosphodiesters [22-26]. Likewise, protein-bound PC-epitopes have been detected in various species of this phylum [20, 27-35]. The mass spectrometric analysis of these PC-substituted biomolecules, however, is often hampered by a significantly lower sensitivity attributable to the zwitterionic character of the PC-substituents, the dominance of fragments derived from the zwitterionic residue, and the absence of structure specific fragment ions [36]. Although PC has been mostly described to be linked to proteins via N-glycans, there is evidence that other types of linkages might also occur as proposed for the aspartyl protease ASP-6 from Caenorhabditis elegans [18, 33, 37-41]. Furthermore, PC might also be directly linked to the protein backbone, similar to the modification of type IV pili of Neisseria gonorrhoea [32-35, 42]. Additionally, 1-O-alkenyl-snglyceryl-3-phosphorylcholine modifications bound via an esterlinkage to placental peptides have been proposed [8].

Investigations on chemically synthesized peptides with the PC residue coupled to amino acid side chains by either phosphoramidate- or azophenyl linkages showed characteristic fragmentation reactions similar to $\mathrm{PC}$-substituted glycosphingolipids, leading to cyclic phosphate derivatives, which are highly stable towards further fragmentation, thus hampering a subsequent localization of the PC-unit [43]. However, attempts to detect PC-substituted peptides from crude proteolytic digests have failed so far.

Here we report a targeted mass spectrometric strategy based on precursor ion scanning and multiple reaction monitoring (MRM) that allows for the very first time the detection of PCsubstituted peptides resulting from a tryptic digest of PCmodified bovine serum albumin (BSA) and on a background of a tryptic digest from a whole proteome. Furthermore, MRMtriggered MS/MS analyses allowed the identification of the peptide and confident localization of the modification site on the peptide backbone. This development will significantly improve the mass spectrometric methodological repertoire for the structural elucidation of PC-epitopes.

\section{Experimental}

\section{Materials}

The synthetic peptide PVQNKFFGLA-amide (CS-01) was purchased from GeneCust (Dudelange, Luxembourg). BSA was from Sigma (Deisenhofen, Germany).

\section{Preparation of PC-Peptides and PC-BSA}

For the synthesis of PC-phosphoramidate conjugates phosphorylcholine $(15 \mu \mathrm{mol}$; calcium chloride salt) was activated by reaction with equimolar amounts of 1-ethyl-3-(3dimethylaminopropyl) carbodiimide (EDC; Sigma) in $0.5 \mathrm{~mL}$ water and incubation at room temperature (RT) for $30 \mathrm{~min}$. For derivatization, $1 \mathrm{mg}(890 \mathrm{nmol})$ of the peptide was added to the EDC-activated PC and incubated for $1 \mathrm{~h}$ at RT [44].

For the synthesis of the PC-azophenyl conjugates, $5 \mathrm{mg} p$ aminophenyl-PC (TCR, Toronto, Canada) was dissolved in 50 $\mu \mathrm{L} 1 \mathrm{M}$ hydrochloric acid containing $1.3 \mathrm{mg}$ sodium nitrite (Merck, Darmstadt, Germany). After $10 \mathrm{~min}$, the reaction mixture was added to $300 \mu \mathrm{L}$ of peptide solution $(500 \mu \mathrm{g}$ peptide in $0.1 \mathrm{M}$ sodium borate, $0.15 \mathrm{M}$ sodium chloride, $\mathrm{pH}$ 9.0) and the reaction was performed under vigorous shaking for $16 \mathrm{~h}$ at $4^{\circ} \mathrm{C}$ [45]. The reaction mixtures were stored at $-20^{\circ} \mathrm{C}$.

The PC-peptides were separated from educts and sideproducts by reversed-phase chromatography on a Reprosil Pur C18 AQ column (4 mm i.d., $150 \mathrm{~mm}$ length, $5 \mu \mathrm{m}$ particle size; Dr. Maisch GmbH, Ammerbuch-Entringen, Germany) using a Hewlett Packard HP1090 HPLC system controlled by ChemStation A.09.01 (both Agilent Technologies, Waldbronn, Germany). Peptides were eluted with a linear gradient of $5 \%$ to $50 \%$ acetonitrile $(\mathrm{ACN})$ in $0.1 \%$ trifluoroacetic acid with a flow rate of $180 \mu \mathrm{L} / \mathrm{min}$ for $60 \mathrm{~min}$ and lyophilized. Yields were calculated based on peak volumes.

Phosphoamidate-coupled PC-BSA was synthesized by activation of phosphorylcholine $(15 \mu \mathrm{mol}$; free acid $)$ with equimolar amounts of 1-ethyl-3-(3-dimethylaminopropyl) carbodiimide (EDC; Sigma) in $0.5 \mathrm{~mL}$ water and incubation at room temperature (RT) for $30 \mathrm{~min}$. For derivatization 15 nmol of BSA was added to the EDC-activated PC and incubated for $1 \mathrm{~h}$ at room temperature [44]. The phosphoamidatecoupled PC-BSA was desalted by NAP5 Columns (GE Healthcare, Freiburg, Germany).

\section{Characterization of PC-modified BSA}

For Western-blotting, proteins were separated on a 15\% SDSpolyacrylamide gel, transferred to a PVDF membrane by semidry blotting, and after blocking with Roti-Block (Roth, Karlsruhe, Germany) the membrane was incubated with the PCspecific antibody TEPC-15 (Sigma, 1:3000 dilution) overnight at $4{ }^{\circ} \mathrm{C}$ in Roti-Block. Afterwards, the membrane was washed four times for $10 \mathrm{~min}$ with PBS-T (PBS containing 0.5\% Tween20), incubated with horseradish peroxidase-conjugated anti-mouse Ig (Dako Cytomation, Hamburg, Germany, 1:3000 dilution) for $1 \mathrm{~h}$ at RT, and again washed four times for $10 \mathrm{~min}$ with Roti-Block. Proteins recognized by the antibody were visualized by enhanced chemiluminescence using the ECL SuperSignal kit (GE Healthcare).

\section{Tryptic Digest}

Coomassie stained protein bands from 1D-gels containing up to $30 \mathrm{pmol}$ of protein were excised and transferred into $100 \mu \mathrm{L}$ 
distilled water in LoBind tubes (Eppendorf, Hamburg, Germany). The gel material was washed 15 min under shaking with $100 \mu \mathrm{L} 50 \mathrm{mM}$ ammonium hydrogen carbonate and destained in the same buffer containing $50 \%$ ACN. After removal of solvent, the gel plugs were shrunk twice by addition of $30 \mu \mathrm{L}$ ACN with intermediate addition of $50 \mu \mathrm{L} 50 \mathrm{mM}$ ammonium hydrogen carbonate. Finally, the gel pieces were dried in a vacuum centrifuge (Savant SpeedVac; GMI Jouan, München, Germany). Reduction was performed by incubation with $50 \mu \mathrm{L}$ dithioerythritol solution (10 $\mathrm{mM}$ in $50 \mathrm{mM}$ ammonium hydrogen carbonate) for $30 \mathrm{~min}$ at room temperature. The supernatant was removed and $50 \mu \mathrm{L}$ of iodoacetamide ( $55 \mathrm{mM}$ in 50 $\mathrm{mM}$ ammonium hydrogen carbonate) were added. After incubation for $30 \mathrm{~min}$ at room temperature, the gel was washed with $100 \mu \mathrm{L} 50 \mathrm{mM}$ ammonium hydrogen carbonate. Gel plugs were shrunk twice by addition of $30 \mu \mathrm{L} \mathrm{ACN}$ with intermediate addition of $50 \mu \mathrm{L} 50 \mathrm{mM}$ ammonium hydrogen carbonate and dried in a vacuum centrifuge. The samples were digested overnight at $37^{\circ} \mathrm{C}$ in $50 \mu \mathrm{L} 25 \mathrm{mM}$ ammonium hydrogen carbonate containing $0.5 \mu \mathrm{g}$ trypsin (sequencing grade; Promega, Mannheim, Germany). Peptides were recovered by washing the gel material with $10 \mu \mathrm{L} 0.1 \%$ trifluoroacetic acid and stored at $-20^{\circ} \mathrm{C}$ until further use.

\section{MALDI-TOF-MS}

MALDI-TOF-MS was performed on an Ultraflex I TOF/TOF mass spectrometer (Bruker Daltonics, Bremen, Germany) equipped with a nitrogen laser and a LIFT-MS/MS facility. The instrument was operated in the positive ion reflectron mode. The matrix consisted of 2,5-dihydroxybenzoic acid (DHB, $5 \mathrm{mg} / \mathrm{mL}$; Sigma) supplemented with methylenediphosphonic acid (5 mg/mL; Fluka, Seelze, Germany) in $0.1 \%$ TFA. Sum spectra consisting of 300-500 single spectra were acquired. For instrument control, data processing, and data analysis the Compass 1.3 software package consisting of FlexControl 2.4, FlexAnalysis 3.0, and BioTools 3.0 (Bruker Daltonics) was used.

\section{Choline Quantification}

PC-residues were removed from PC-BSA by cleavage of the phosphoester bonds with hydrogen fluoride: $10 \mathrm{mg}(151 \mathrm{nmol})$ of lyophilized PC-BSA was dissolved in $500 \mu \mathrm{L}$ of hydrofluoric acid (48\%, Merck) and incubated on ice overnight. The sample was dried under a stream of nitrogen, dissolved in $500 \mu \mathrm{L}$ of water, and lyophilized three times. Choline was measured by HPLC according to published methods [46].

\section{Analysis of a PC-Derivatized BSA Digest}

A tryptic in-gel digest of PC-labeled of bovine serum albumin was separated on a Tempo 1D nanoLC system (AB SCIEX, Darmstadt, Germany). A nominal amount of 500 fmol starting material was loaded onto a Reversed Phase-C18 (RP-C18) trap column (Acclaim Pepmap100-C18, $5 \mu \mathrm{m}$ particle size, $300 \mu \mathrm{m}$ i.d., $5 \mathrm{~mm}$ length; Dionex, Thermo Scientific, Dreieich,
Germany) and desalted using $100 \mu \mathrm{L}$ of $0.5 \%$ (vol/vol) formic acid (FA) $/ 2 \%$ (vol/vol) ACN. Separation was achieved by back-flush gradient elution onto a RP-C18 microcolumn (Acclaim Pepmap $100 \mathrm{C} 18,3 \mu \mathrm{m}$ particle size, $75 \mu \mathrm{m}$ i.d., $150 \mathrm{~mm}$ length) using a $30 \mathrm{~min}$ linear gradient of $5 \%-45 \%$ (vol $/ \mathrm{vol}$ ) $\mathrm{ACN} / 0.1 \%$ (vol $/ \mathrm{vol}$ ) FA, $250 \mathrm{~nL} / \mathrm{min}$. The eluent was analyzed on a 4000 Q TRAP LC/MS/MS system equipped with a Nanospray II source and operated under Analyst 1.4.1 software (all AB SCIEX). Data visualization and annotation were performed using Bioanalyst 1.4.1 and PeakView 2.1 software (AB SCIEX).

\section{Precursor Ion Scanning Experiments}

PC-modified peptides were selectively detected using two consecutive precursor ion scanning experiments per cycle for $\mathrm{m} / \mathrm{z}$ 104.1 (choline $\mathrm{C}_{5} \mathrm{H}_{14} \mathrm{NO}$ ) and $m / z 184.1$ (phosphorylcholine $\left.\mathrm{C}_{5} \mathrm{H}_{15} \mathrm{NO}_{4} \mathrm{P}\right)$ in positive ion mode, respectively. For each precursor ion scan, $m / z$ range $400-1200$ was scanned using a scan time of $2.5 \mathrm{~s}$ and fixed collision energies of 55 and $50 \mathrm{eV}$, respectively. Up to the five most abundant signals detected in either precursor ion scan were then submitted to a highresolution linear ion-trap MS scan to determine the corresponding monoisotopic mass, charge state, and molecular weight, resulting in a maximum cycle time of $6 \mathrm{~s}$.

\section{MRM Optimization of Collision Energy}

MRM transitions were set up in positive ion mode for nine putative PC-modified precursors showing a response in both the $m / z 104$ and 184 precursor ion scans. For each precursor/ fragment pair, six transitions were used at collision energies stepped from 30 to $80 \mathrm{eV}$ in steps of $10 \mathrm{eV}$, resulting in a total of 108 transitions, which were monitored in two separate runs with 54 transitions each using a dwell time of $40 \mathrm{~ms}$ and unit resolution (0.7 FWHM) in both quadrupoles. In both runs, MRM transitions showing threshold intensity were confirmed by data-dependent high resolution linear ion trap MS scans, and Enhanced Product Ion (EPI) MS/MS scans employing Q2 collision-cell activation using rolling collision energy, nitrogen as collision gas, and recording of the fragments at a scan speed of $4000 \mathrm{Da} \mathrm{s}^{-1}$ in the Q3 linear ion trap. For each of the nine putative precursors, the best collision energy was selected; averaging across precursors provided best values of $+55 \mathrm{eV}$ for transitions to $\mathrm{m} / \mathrm{z} 104.1$ and $+50 \mathrm{eV}$ for transitions to $\mathrm{m} / \mathrm{z}$ 184.1 , respectively.

\section{MRM-Triggered MS/MS Experiments}

For identification and site localization, MRM transitions for 17 putative PC-modified peptide precursors identified in the precursor ion scanning experiment to $\mathrm{m} / \mathrm{z} 104.1$ and 184.1 were monitored, resulting in a total of 34 transitions (Table 1). Q1 masses were in the range of $m / z$ 440-690 for doubly charged precursors, and in the range of $m / z 410-660$ for triply charged precursors. MRM transitions were designed using the optimized collision energies of 55 and $50 \mathrm{eV}$, respectively, unit 
Table 1. 34 MRM transitions for 17 candidate PC-peptides derived from precursor ion scan experiments of a tryptic digest of PC-modified BSA

\begin{tabular}{|c|c|c|c|c|}
\hline Q1 & Q3 & $\mathrm{CE}[\mathrm{eV}]$ & $\begin{array}{l}\text { Dwell } \\
\text { time }[\mathrm{ms}]\end{array}$ & $\begin{array}{l}\text { Identified by } \\
\text { MS/MS }\end{array}$ \\
\hline 684.3 & 184.1 & 50 & 50 & No \\
\hline 684.3 & 104.1 & 55 & 50 & \\
\hline 606.8 & 184.1 & 50 & 50 & No \\
\hline 606.8 & 104.1 & 55 & 50 & \\
\hline 652.2 & 184.1 & 50 & 50 & CCTESLVNR \\
\hline 652.2 & 104.1 & 55 & 50 & \\
\hline 654.0 & 184.1 & 50 & 50 & RKVPQVSTPTLVEVSR \\
\hline 654.0 & 104.1 & 55 & 50 & \\
\hline 477.8 & 184.1 & 50 & 50 & No \\
\hline 477.8 & 104.1 & 55 & 50 & \\
\hline 546.8 & 184.1 & 50 & 50 & YLYEIAR \\
\hline 546.8 & 104.1 & 55 & 50 & \\
\hline 590.3 & 184.1 & 50 & 50 & QTALVELLK \\
\hline 590.3 & 104.1 & 55 & 50 & \\
\hline 548.8 & 184.1 & 50 & 50 & No \\
\hline 548.8 & 104.1 & 55 & 50 & \\
\hline 603.3 & 184.1 & 50 & 50 & No \\
\hline 603.3 & 104.1 & 55 & 50 & \\
\hline 487.3 & 184.1 & 50 & 50 & No \\
\hline 487.3 & 104.1 & 55 & 50 & \\
\hline 449.8 & 184.1 & 50 & 50 & No \\
\hline 449.8 & 104.1 & 55 & 50 & \\
\hline 416.6 & 184.1 & 50 & 50 & No \\
\hline 416.6 & 104.1 & 55 & 50 & \\
\hline 602.3 & 184.1 & 50 & 50 & KVPQVSTPTLVEVSR \\
\hline 602.3 & 104.1 & 55 & 50 & \\
\hline 535.7 & 184.1 & 50 & 50 & No \\
\hline 535.7 & 104.1 & 55 & 50 & \\
\hline 445.6 & 184.1 & 50 & 50 & No \\
\hline 445.6 & 104.1 & 55 & 50 & \\
\hline 667.9 & 184.1 & 50 & 50 & No \\
\hline 667.9 & 104.1 & 55 & 50 & \\
\hline 584.3 & 184.1 & 50 & 50 & LVVSTQTALA \\
\hline 584.3 & 104.1 & 55 & 50 & \\
\hline
\end{tabular}

resolution in both quadrupoles and dwell times of $50 \mathrm{~ms}$. On exceeding a threshold intensity of $2500 \mathrm{cps}$, up to two precursors were confirmed using high resolution linear ion trap MS and enhanced product ion MS/MS scans.

\section{Identification of PC-Modified Proteins by Sequence Database Searching}

Product ion spectra from the MRM-triggered MS/MS experiments were searched against the complete Bos taurus proteome UniProt sequence database (revision 08/14, 24139 entries) supplemented by 50 common lab contaminants using ProteinPilot 4.5.0.0 software (Build 1656; AB SCIEX). N-/ $\mathrm{O}-/ \mathrm{S}-$ modification of phosphorylcholine was introduced to the software's data dictionary and added to the "Special Factors: Gel-based ID" modification set at a feature probability of $49 \%$, reflecting the specificity of the MRM detection.

\section{Detection of PC-Modified Peptides in a Full Proteome Digest}

PC-labeled peptides (PC coupled as amidate and azophenyl to CS-01) were dissolved in $10 \mathrm{mM}$ ammonium formate to a final concentration of $2 \mathrm{pmol} / \mu \mathrm{L}$ and analyzed either alone or spiked into a total digest of Arabidopsis thaliana (500 pmol of each synthetic peptide and $1 \mu \mathrm{g} A$. thaliana digest, respectively). Peptides were separated by an HPLC system (Eksigent ekspert nanoLC 400 system, AB SCIEX, Darmstadt, Germany) connected to a QTRAP $4500 \mathrm{LC} / \mathrm{MS} / \mathrm{MS}$ system equipped with a NanoSpray III source and operated under Analyst 1.6 software. HPLC was performed on a C18 column (Acclaim Pepmap100 C18, $2 \mu \mathrm{m}$ particle size, $75 \mu \mathrm{m}$ i.d., $250 \mathrm{~mm}$ length; Dionex, Thermo Scientific). A linear gradient of $10 \%$ to $30 \% \mathrm{ACN}$ in $0.1 \%$ formic acid was applied to elute the peptides at a flow rate of $300 \mathrm{~nL} / \mathrm{min}$ within $60 \mathrm{~min}$. All mass spectrometry measurements were done in nano positive ion spray mode (ion spray voltage $2800 \mathrm{~V}$ ). The modified peptides could be first detected by precursor ion scanning for the typical fragments choline and phosphorylcholine $(\mathrm{m} / \mathrm{z} 104.1$ and 184.1 , respectively), which triggers an enhanced product ion scan (MS/MS) in the linear ion trap for peptide identification (scan speed $10000 \mathrm{Da} \mathrm{s}^{-1}$ ). The precursor ion scan was done with a Q1 scan speed of 1000 $\mathrm{Da} \mathrm{s}^{-1}$, the collision energy was ramped between $70-90 \mathrm{eV}$ for fragment $\mathrm{m} / \mathrm{z} 104.1$ and between 50 and $70 \mathrm{eV}$ for fragment $\mathrm{m} / \mathrm{z}$ 184.1. Additional data were acquired by MRM-triggered enhanced product ion (EPI) scans to further verify the results of the first experiment. The MRM was built by the detected or calculated phosphorylcholine modified peptide precursors mass (Q1 mass) and the specific fragments $\mathrm{m} / \mathrm{z} 104.1$ and 184.1 Da (Q3 mass). A positive MRM signal triggered an Enhanced Product Ion MS/MS scan with fragment detection in the linear ion trap. Data were analyzed with PeakView 2.1 (both from AB SCIEX).

\section{Results and Discussion}

Synthesis and Purification of PC-substituted Peptides and Proteins, and Characterization of the Products by MALDI-TOF-MS

Essentially, two one-step methods have been described for the synthesis of PC-modified peptides and proteins: first, PC becomes activated by a carbodiimide-derivative and is subsequently coupled to the side chains of polar amino acids, resulting in phosphoamidate- (lysine) and phosphoester- (serine, threonine, and tyrosine) linkages (Figure 1a). A second method is the reaction of $p$-aminophenyl-PC via activation as diazonium-derivative to the side chains of tyrosine and histidine (Figure 1b). Furthermore, this diazonium-derivative can also react with lysine. However, in case of the $\varepsilon$-aminogroup of lysine as an acceptor, the resulting linkage is not a diazo-group but a secondary amine-bond and referred to as $\mathrm{PC}^{*}$ in the following (Figure 1b). For PC-modification we used peptides that were amidated at their $\mathrm{C}$-terminus, to avoid carboxyl groups for the phosphoamidate method, which would otherwise result in carbodiimide-catalyzed polymerization of the peptide.

For PC-derivatization, we used a synthetic peptide (CS-01; PVQNKFFGLA-amide) lacking a free primary amino-group at the $\mathrm{N}$-terminus, a free $\mathrm{C}$-terminus, and other functional groups 
(a)<smiles>[R]CCCCN(C)P(=O)([O-])OCC[N+](C)(C)C</smiles><smiles>[R]COP(=O)([O-])OCC[N+](C)(C)C</smiles><smiles>[R]C(C)OP(=O)([O-])OCC[N+](C)(C)C</smiles>

PC-Thr

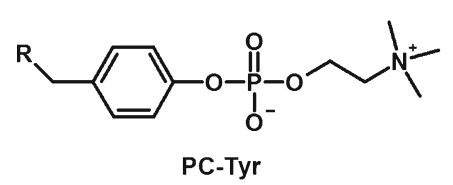

(b)<smiles>[R]Cc1ccc(O)c(N=Nc2ccc(OP(=O)([O-])OCC[N+](C)(C)C)cc2)c1</smiles><smiles>[R]Cc1cnc(N=Nc2ccc(OP(=O)([O-])OCC[N+](C)(C)C)cc2)[nH]1</smiles><smiles>[R]CCCCNc1ccc(OP(=O)([O-])OCC[N+](C)(C)C)cc1</smiles>

(c)<smiles>C[N+](C)(C)CCO</smiles>

Cho $(m / z$ 104.1)<smiles>C[N+](C)(C)CCOP(=O)(O)O</smiles>

PC $(m / z$ 184.1)

Figure 1. Synthetic PC-epitope structures generated by phosphoamidate- (a) or diazo coupling (b). Structures from carbodiimidechemistry resulted in phosphoamidate- (Lys) or phosphoester- (Ser, Thr, Tyr) linkages to the peptide backbone (a), whereas diazocoupling resulted in modifications of Tyr, His and Lys (b). The side-chain of the modified amino acid is shown and $\mathrm{R}$ represents the rest of the peptide or protein. PC*: in case of diazo-coupling to Lys, the resulting molecule contains a secondary amine instead of a diazo-group. (c) Structures of the marker ions choline $(\mathrm{m} / \mathrm{z} 104.1)$ and phosphorylcholine $(\mathrm{m} / \mathrm{z} 184.1)$ characteristic for the fragmentation of PC-substituted peptides

at the side chains to prevent extensive side reactions. Derivatization of the peptide CS-01 $\left([\mathrm{M}+\mathrm{H}]^{+}\right.$observed at $\left.\mathrm{m} / \mathrm{z} 1119.5\right)$ with both methods resulted in products named as CS-01-PC (phosphoamidate-coupling; $[\mathrm{M}+\mathrm{H}]^{+}$at $m / z$ 1284.6 Da, Figure 2a) and CS-01-PC* (diazo-coupling; $[\mathrm{M}+\mathrm{H}]^{+}$at $m / z$ 1376.7, Figure 2c) with yields of $62 \%$ and $10 \%$, respectively, as determined by the HPLC-purification.

The two different PC-modified peptides were analyzed by MALDI-MS/MS. The spectra (Figure $2 b$ and $d$ ) showed strong signals for the fragments of choline $(\mathrm{m} / \mathrm{z} 104.1)$ and phosphorylcholine $(\mathrm{m} / \mathrm{z} 184.1$; Figure $1 \mathrm{c})$ as well as fragment ions resulting from the neutral loss of $59 \mathrm{Da}$, attributable to a Hoffmann elimination of trimethylamine from the choline moiety and formation of a cyclic phosphodiester [43]. Especially in the case of the phosphoamidate, the preferential fragmentation of the PC moiety lead to poor fragmentation of the peptide backbone, resulting in weak signals of the a-, b-, and y-ion series in the MS/MS spectra (Figure 2b). This situation parallels the observation of the fragment ion series containing dehydroalanine when CID-induced phosphoric acid loss from phosphoserine has taken place [47]. The diazo-coupled peptide exhibited less Hoffman elimination; here the fragments cover the whole sequence (Figure 2d). Nevertheless, for both peptides the PC-substituent could be unambiguously localized to the lysine residue (assigned as $\mathrm{K}^{*}$ in Figure $2 \mathrm{~b}$ and $\mathrm{d}$ ), by $\mathrm{b} 4$ and $\mathrm{b} 5(\mathrm{~m} / \mathrm{z} 439.3$ and 732.8 , respectively) ions in the case of
CS-01-PC (Figure 2b) and a4, a5, b4, and b5 ( $\mathrm{m} / \mathrm{z} 411.3,795.6$, 438.6 , and 823.8, respectively) in the case of the CS-01-PC* (Figure 2d).

These investigations clearly demonstrated the dominant influence of PC-substituents on the mass spectrometric fragmentation. The neutral loss of the trimethylamine group (M-59) resulted in cyclic phosphate derivatives. This Hoffmann elimination was also found for trimethylated lysine residues of histones and acylcarnitines $[25,26]$. The cyclic phosphate derivative formed in the case of PC-substituents seems to trap the positive charge very strongly, thus suppressing the formation of peptide specific fragment ions. In contrast, fragmentation of the peptide backbone was not affected in the case of the tri- $N$-methylated lysines in histones since respective cyclic phosphate derivatives were not formed in that case. When ion trap instruments are used, ion traces of $\mathrm{m} / \mathrm{z} 104.1$ and $m / z 184.1$ can hardly be used because low mass ions are often absent or of low intensity. Here, a neutral loss scan (M-59) can be used to screen complex peptide mixtures for the presence of PC-substitutions for a selection of these peptides for MS/MS analyses [43].

As a third and more complex derivative, we modified BSA with PC using the phosphoamidate chemistry. The coupling was verified by a Western blot experiment, detecting the PCmodification with the PC-specific antibody TEPC-15 (Figure 2e). After cleavage of the phosphodiester bonds with hydrogen 


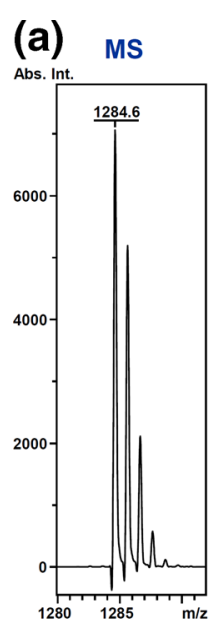

(b)
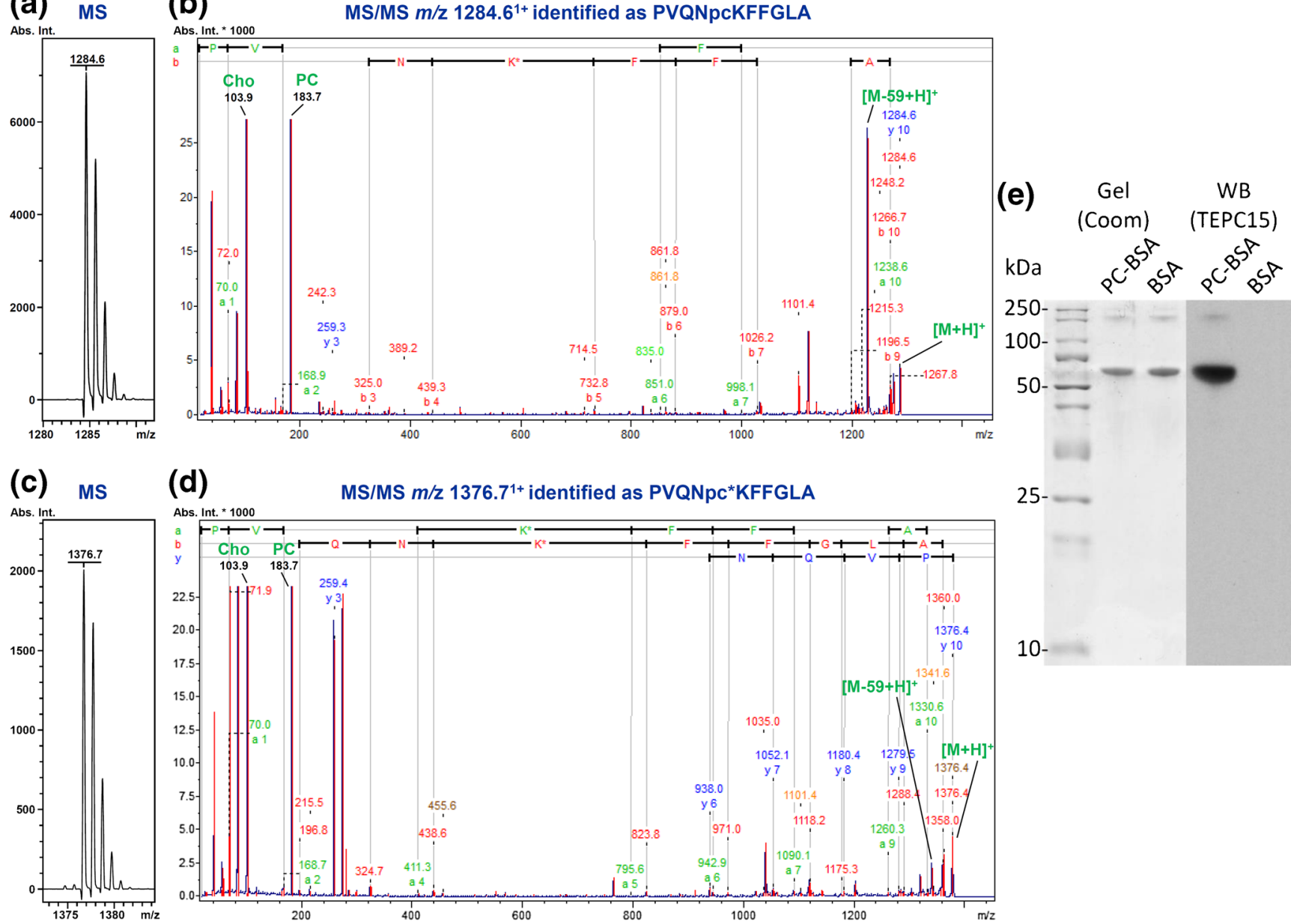

(d)

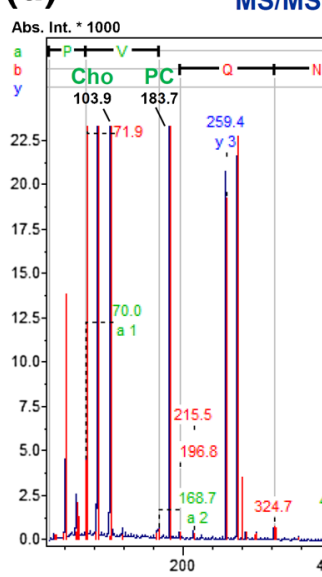

MS/MS m/z 1376. $7^{1+}$ identified as PVQNpc*KFFGLA

$25-$

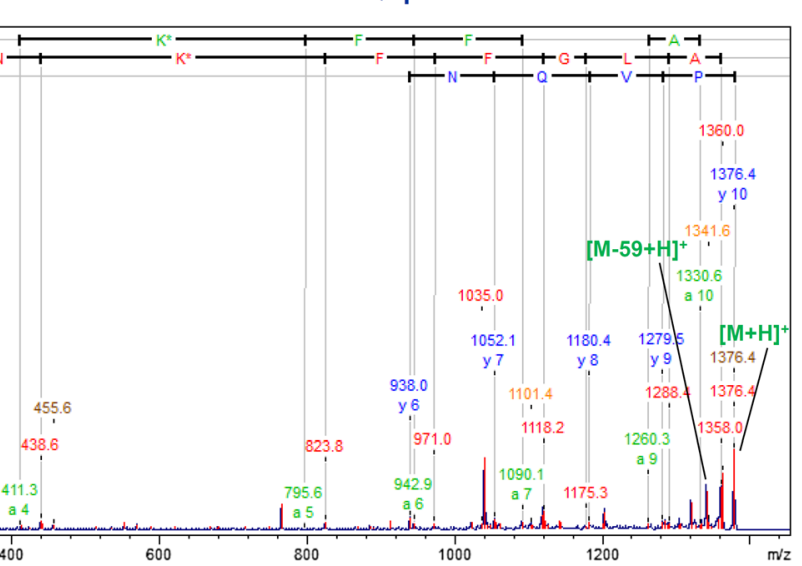

$10-$

Figure 2. Characterization of synthetic PC-peptides and proteins by MALDI-TOF-MS and Western blot. MALDI-TOF-MS and MS/ MS spectra of the PC-modified peptide CS-01 (a)-(d). The MS/MS spectra of the phosphoamidate- (b) and the diazo-derivative (d) show strong signals for choline $\left(\mathrm{m} / z\right.$ 104.1) and PC $\left(\mathrm{m} / z\right.$ 184.1). In addition to the $[\mathrm{M}+\mathrm{H}]^{+}$ions $(\mathrm{m} / z 1284.6$ and 1376.7$)$, fragment ions resulting from the neutral loss of $59 \mathrm{Da}$ (Hoffman elimination of trimethylamine) were observed. (e) The Coomassie-stained gel with PC-BSA and unmodified BSA and the respective Western blot with the PC-specific antibody TEPC-15 showing a strong positive signal in case of PC-BSA

fluoride, a substitution of 591 pmol PC per 151 pmol BSA — giving a molar ratio of 3.9 - could be determined by quantifying the amount of choline released as described in [46]. For analysis by MRM-triggered MS, we digested the PC-BSA with trypsin, yielding a complex but defined mixture of PCmodified and unmodified peptides.

\section{Development of a LC/MS/MS Workflow for the Detection and Localization of PC-Substituents}

Although the detection and localization of PC with MALDIMS/MS works well for single peptides, this method was found to be not suitable for the analysis of complex peptide mixtures from proteolytic digests of PC-modified proteins where usually only a small number of peptides carries the modification in sub stoichiometric amounts.

Based on the observation that MS/MS-fragmentation of PCmodified peptides usually generates strong signals for choline $(\mathrm{m} / \mathrm{z}$ 104.1) and phosphorylcholine $(\mathrm{m} / \mathrm{z} 184.1)$, we developed a two-stage workflow for the detection and localization of PCmodifications in peptides by nanoLC/MS/MS on hybrid triple quadrupole/linear ion trap (QTRAP) mass spectrometers.

MRM-triggered MS/MS acquisition has been previously described as a powerful tool for the detection of posttranslational protein modifications such as phosphorylation [48, 49], acetylation [50], and ubiquitination [51]. In the so-called MIDAS approach (MRM-initiated detection and sequencing), the MRM Q1 masses corresponding to the modified peptide are usually predicted theoretically if both an exact protein sequence and the specificity of the modification are known. Especially for less site-specific or heterogeneous modifications, a modification-specific precursor ion scan can be used to confine the otherwise rapidly expanding list of potential precursor masses in a scouting experiment. This two-stage workflow has been described for the successful analysis of covalent peptide-RNA crosslinks [52]. Applying this approach to the detection of PC-modified peptides, we here used two consecutive precursor ion scans for the $m / z$ 104.1/184.1 marker ions to 
detect potential PC-peptide candidates. Data-dependent high resolution linear ion trap scans were used to determine the charge states and molecular masses of these candidates (Figure 3, top). In a second experiment, MRM transitions from the detected candidates' $\mathrm{m} / \mathrm{z}$ to the $\mathrm{m} / \mathrm{z}$ 104.1/184.1 marker ions were used to trigger MS/MS experiments under optimal conditions (i.e., close to the LC peak apex) (Figure 3, bottom). In addition, an overlay of the candidates' $\mathrm{m} / \mathrm{z} 104.1$ and $\mathrm{m} / \mathrm{z} 184.1$ traces should be used to confirm the presence of the PC modification on the peptide.

\section{Optimization of CID-Fragmentation Conditions for the Detection of PC-Substituted Peptides}

The CID collision energy used for precursor ion scanning and MRM were optimized using candidate peptides from the PCBSA digest. Production of the marker ions as a function of collision energy was monitored using six MRM transitions per precursor and fragment with collision energies ranging from 30 to $80 \mathrm{eV}$ in steps of $10 \mathrm{eV}$. By observing the best values and averaging across nine precursors, best values of 55 and $50 \mathrm{eV}$ were found as the optimum collision energy values for production of $\mathrm{m} / \mathrm{z} 104.1$ and 184.1, respectively (Figure 4).
Application of the LC/MS/MS Workflow for the Detection and Localization of PC-substituted Peptides within a Model Tryptic Digest of PC-BSA

In the next experiment, we applied the optimized settings to identify PC-substituted peptides within a complex peptide mixture and to localize the PC-modification within the peptide sequence using MRM-triggered collision cell CID MS/MS spectra. From the previous precursor ion scan experiments, 17 candidate precursor ions showing response both in the $\mathrm{m} / \mathrm{z}$ 104.1 and 184.1 precursor ion scans were selected and targeted by MRM transitions using the optimized collision energy regime (Table 1, Figure 5a). High resolution linear ion trap MS spectra as well as collision cell CID-MS/MS spectra that were triggered from MRM channels exceeding threshold intensity were acquired to achieve peptide identification and site localization.

A sequence database search including phosphorylcholine as a variable N-/O-/S- modification against the complete Bos taurus proteome returned only the target protein BSA at $>95 \%$ confidence, reflecting the specificity of the targeted MRM detection and the quality of the product ion spectra. From the MRM-triggered MS/MS spectra, various PCmodified BSA peptides could be confidently assigned by sequence database searching and manual review (Table 2).

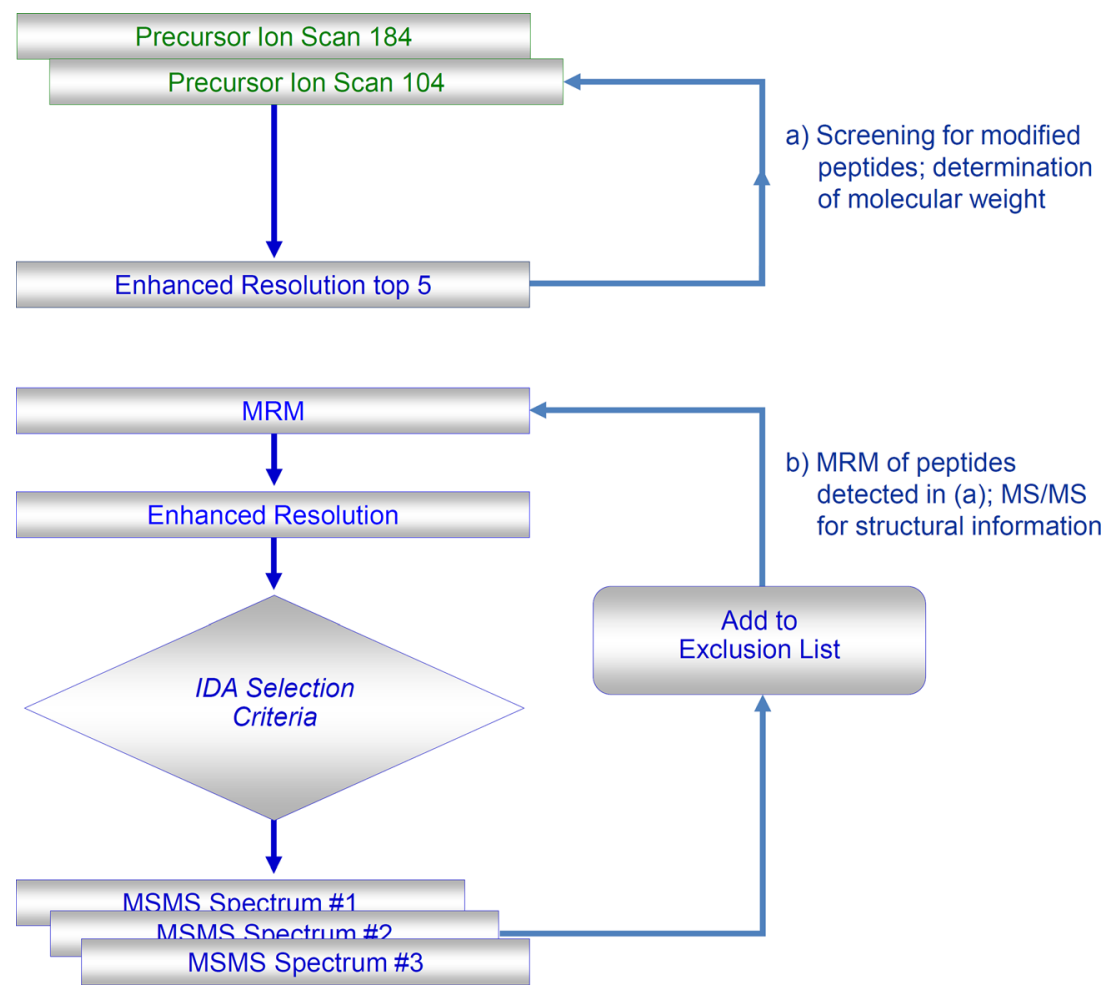

Figure 3. LC/MS/MS workflow for the detection and localization of PC-modifications. In a first HPLC run precursor ion scans for choline $(\mathrm{m} / \mathrm{z} 104 \mathrm{Da})$ and phosphorylcholine $(\mathrm{m} / \mathrm{z} 184 \mathrm{Da})$ generated under optimized CID-conditions were used to detect PCmodified peptides, followed by a high resolution linear ion trap MS-scan to determine the charge state and the molecular weight of the PC-modified precursor. In a second experiment, MRM-triggered MS/MS spectra of these precursors were recorded under optimal conditions. IDA = information-dependent acquisition 


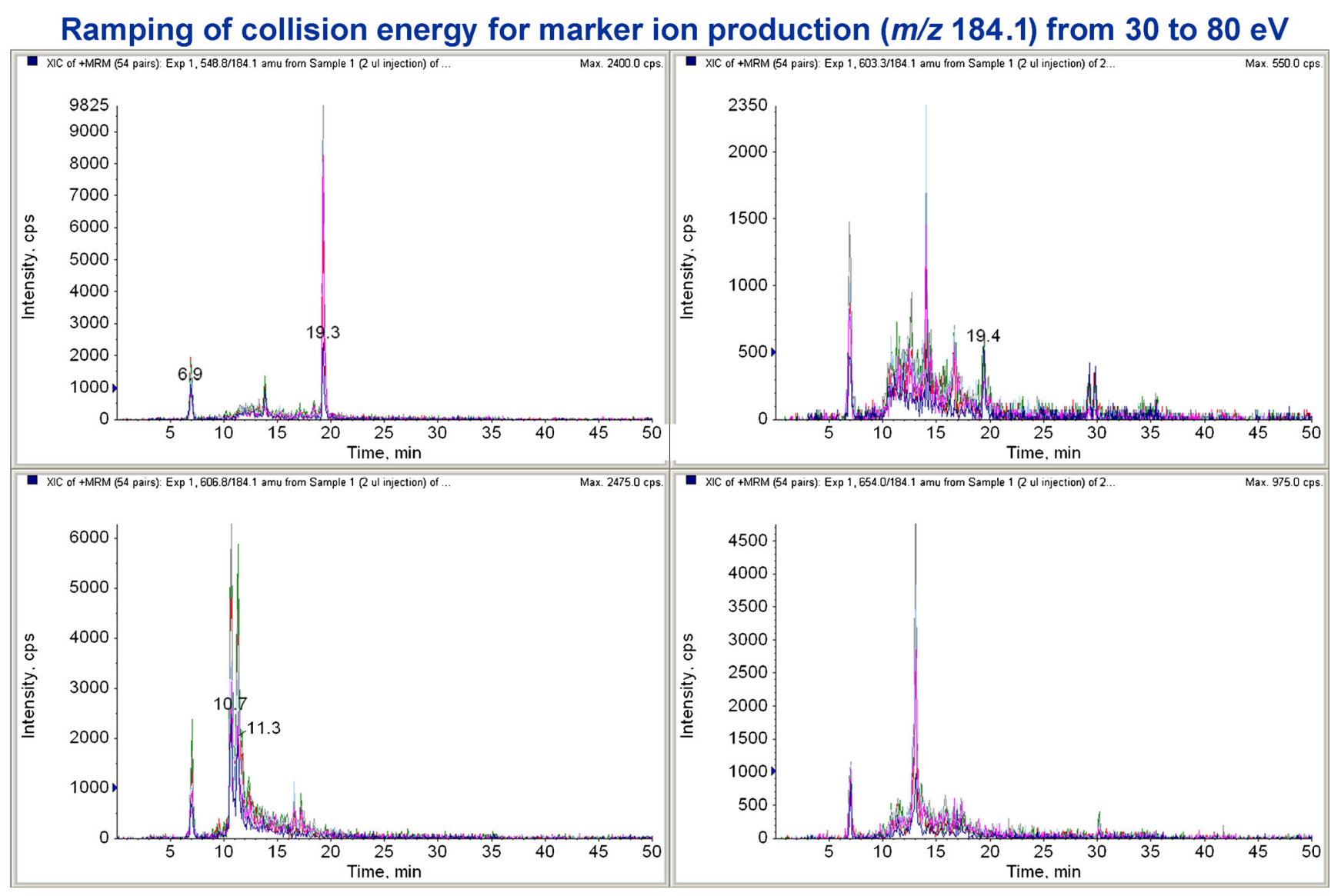

Figure 4. Parameter optimization for the detection and fragmentation of PC-peptides. The CID collision energy used for precursor ion scanning and MRM-triggered fragmentation was optimized using four candidate peptides from a tryptic digestion of PC-BSA. Collision energies of 55 and $50 \mathrm{eV}$, respectively, were found as optimal for the production of $\mathrm{m} / \mathrm{z} 104$ and 184 fragments and fragmentation

Markedly, only one non-PC-modified peptide was identified. Figure 5b-e show four examples for peptides carrying PC epitopes on Lys, Tyr, and Thr, respectively. Most of the CID spectra obtained showed strong fragments that could be attributed to the neutral loss of choline or the complete phosphorylcholine moiety, i.e., $[\mathrm{M}+\mathrm{H}-103]^{+}$(loss of choline) and $[\mathrm{M}+\mathrm{H}-183]^{+}$(loss of phosphorylcholine), plus abundant signals for the marker ions for choline $(\mathrm{m} / \mathrm{z}$ 104.1) and phosphorylcholine $(\mathrm{m} / \mathrm{z}$ 184.1). This fragmentation pattern confirmed the PC-substitution. Lys-derivatized peptides show a higher relative intensity of sequence-specific b- and y-type fragment ions versus the marker ions, indicating a higher stability of the N-derivatization under CID conditions compared to the O-derivatization in PC-Tyr/PC-Thr-epitopes. In comparison to the MALDI-MS/MS analyses shown above, it seemed that the Hoffmann elimination was reduced under these experimental conditions; therefore, more sequence-specific fragment ions were generated, which facilitates sequence identification and localization of the PC modification site. Additional confirmation for the PC-substitution can be drawn from the MRM intensity ratios for the $\mathrm{m} / \mathrm{z} 104$ and 184 transitions of each precursor, respectively. For the successfully identified peptides, we consistently observed 104/184 intensity ratios between $3 / 1$ and 10/1, irrespective of the modified residue, precursor $m / z$, or position of the modified residue.

Besides the seven PC-modified peptides identified in the experiment, more high quality MS/MS data were acquired for the other targeted precursors; however, no further sequences could be assigned. We believe that this is a consequence of the presence of abundant fragment ions in the MS/MS spectra that are specific for loss of the PC modification rather the peptide sequence, especially for O-modified peptides. As nonsequence-specific fragments do not contribute to the scoring, this would also explain the partially low confidence scores assigned by the Paragon algorithm to the identified peptides (Table 2). Improvements on the scoring function or the use of alternative fragmentation techniques might be used to improve this in future experiments.

\section{Detection and Localization of PC-Substituted Peptides within a Complex Tryptic Digest of Arabidopsis thaliana}

In this experiment, we tested the detection of PC-modified peptides in a more realistic proteomic situation: The two PCpeptides CS-01-PC and CS-01-PC* where spiked into the total 
(a) Multiple Reaction Monitoring 17 pairs (Prec $>104)+($ Prec $>184)$

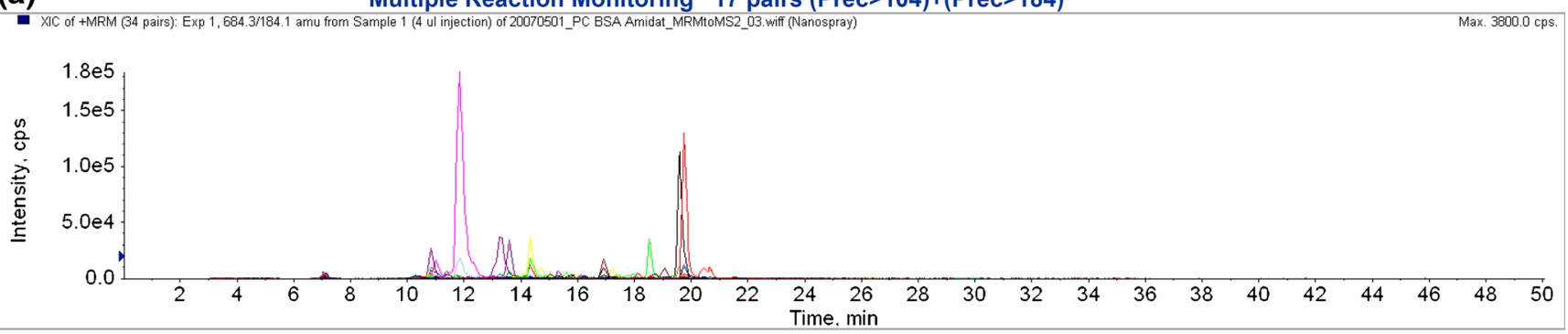

(b) $\mathrm{MS} / \mathrm{MS} \mathrm{m} / \mathrm{z} 602.3^{3+}$ identified as PcKVPQVSTPTLVEVSR

(c) MS/MS $m / 2546.8^{2+}$ identified as PcYLYEIAR
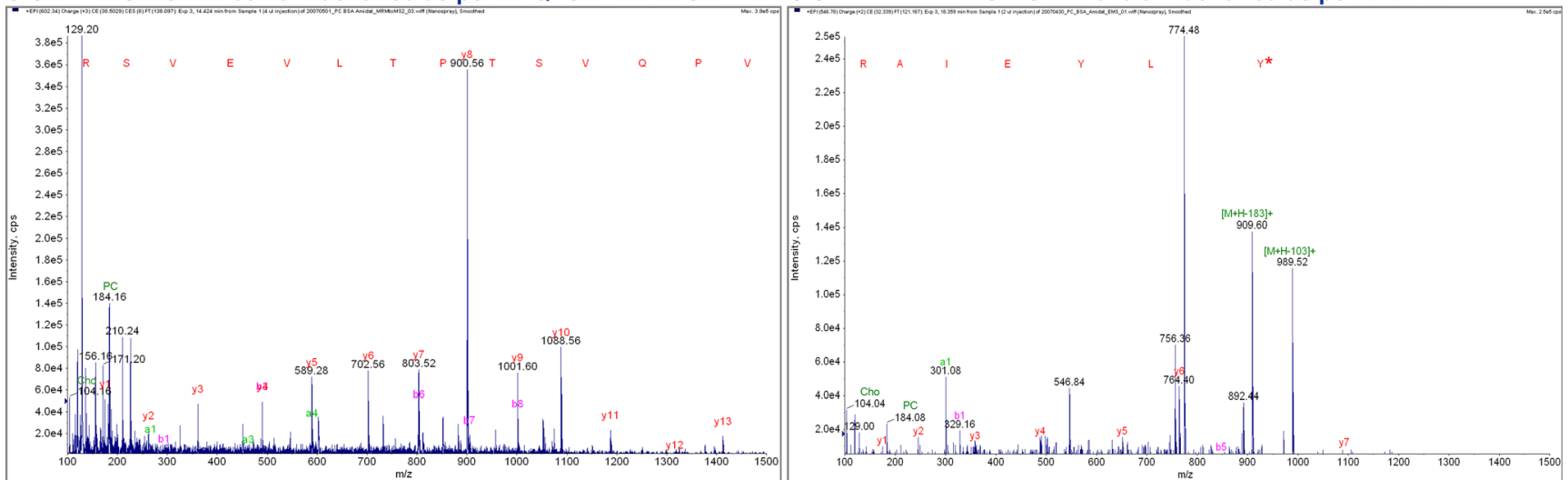

(d)

MS/MS m/z 590.4²+identified as QpcTALVELLK

(e)

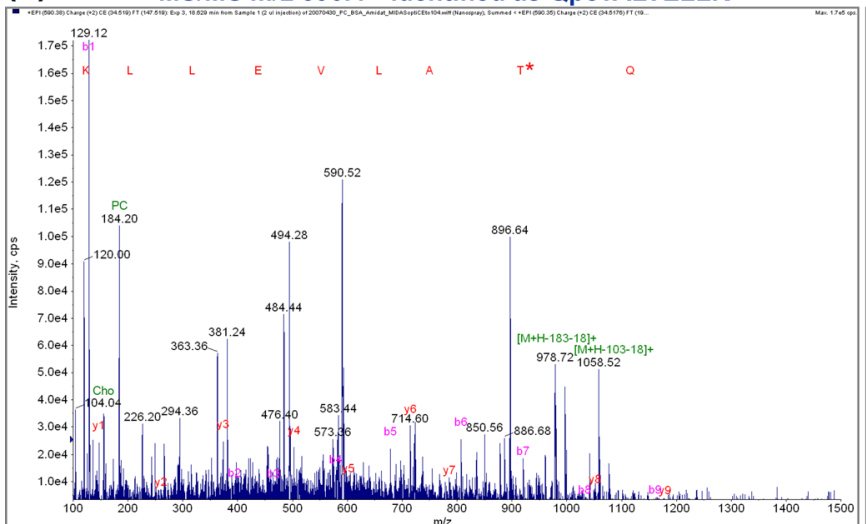

MS/MS m/z 652.32+ identified as CCpcTESLVNR

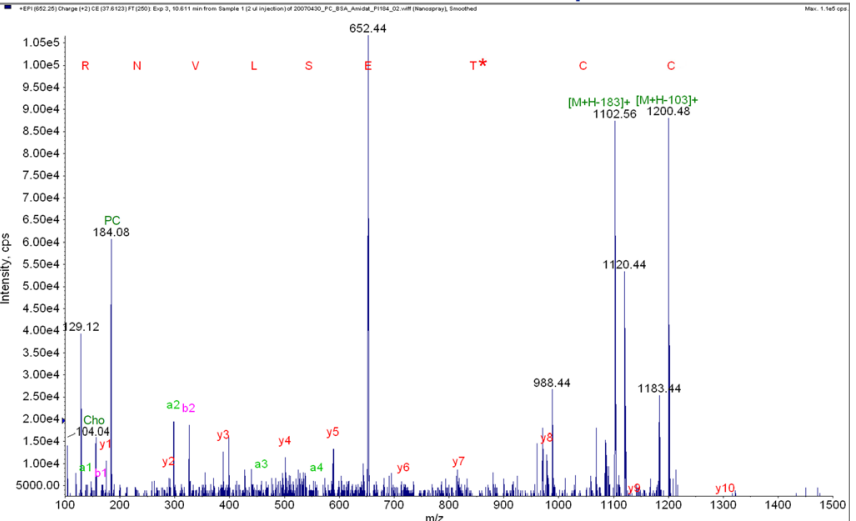

Figure 5. MIDAS-LC/MS/MS MRM profile of the tryptic digest of PC-BSA and selected MS/MS spectra from PC-substituted peptides. (a) Precursor ion scan profiles of the tryptic digest of PC-BSA for precursor ions giving fragments for choline $(\mathrm{m} / z$ 104.1) and phosphorylcholine ( $m / z$ 184.1). (b)-(e) MS/MS-spectra of selected PC-modified peptides from PC-BSA found in the precursor ions scans. Spectra are characterized by strong fragment ion signals resulting from the loss of the choline or phosphorylcholine moieties $\left([\mathrm{M}+\mathrm{H}-103]^{+}\right.$or $\left.[\mathrm{M}+\mathrm{H}-183]^{+}\right)$and the marker ions $\mathrm{m} / \mathrm{z} 104.1$ and $184.1 \mathrm{Da}$. The fragmentation patterns allowed an unambiguous localization of the PC-modification within the sequences

tryptic digest of Arabidopsis thaliana (500 pmol of each synthetic peptide and $1 \mu \mathrm{g} A$. thaliana digest, respectively) and analyzed with the AB SCIEX QTRAP 4500 LC/MS/MS system, the successor of the QTRAP4000. The QTRAP 4500 is characterized by an at least 3-fold increased sensitivity and faster scanning capabilities.

By adjusting the settings from the QTRAP 4000 to the QTRAP 4500, we obtained CID spectra triggered by the MRM traces, which we could unambiguously assign to the two PC-substituted peptides. Figure 6a shows the total ion chromatogram with the CS-01-PC* (azophenyl-PC derivative) and the CS-01-PC (PC-amidate derivative) eluting at $34.46 \mathrm{~min}$ and $45.04 \mathrm{~min}$, respectively. Figure $6 \mathrm{~b}$ and c display the MIDAS-profiles with the simultaneous occurrence of the marker fragments for choline and phosphorylcholine $(\mathrm{m} / \mathrm{z} 104.1$ and $184.1 \mathrm{Da})$ at the time points indicated above. The corresponding CID spectra showed strong fragments that could be assigned to single- and double-charged b- and yfragment ions, with the double-charged fragment ions displaying higher intensities (Figure 6d, E; $\mathrm{b}^{2+}$-ions shown in cyan, $\mathrm{y}^{2+}$-ions shown in purple). In both peptides, the PCsubstituent could be unambiguously allocated to the lysine residue (assigned as $\mathrm{K}^{*}$ in Figure $6 \mathrm{~d}$ and e). Indicative ions were the b4, b5, y5, and y6 fragments $(m / z 439.23,824.49$, 
Table 2. Peptides Identified by Sequence Database Searching from an MRM-Triggered MS/MS Analysis of a Tryptic Digest of PC-Modified BSA

\begin{tabular}{|c|c|c|c|c|c|c|c|c|c|c|}
\hline $\mathrm{N}$ & $\begin{array}{l}\text { Conf. }^{1} \\
{[\%]}\end{array}$ & Sequence & Modifications $^{2}$ & Non-tryptic cleavages & $\mathrm{RT}[\mathrm{min}]$ & $\mathrm{z}$ & $m / z($ exp.) & $m / z$ (theor.) & $\Delta \mathrm{m}[\mathrm{Da}]$ & $\begin{array}{l}\text { MW (theor.) } \\
\text { [Da] }\end{array}$ \\
\hline 1 & 96.5 & KVPQVSTPTLVEVSR & PC(K)@1 & & 14.4 & 3 & 602.32 & 602.34 & 0.02 & 1803.99 \\
\hline 4 & 0.6 & LVVSTQTALA & PC(S)@4 & & 20.5 & 2 & 583.82 & 584.32 & 0.50 & 1166.63 \\
\hline 5 & 0.5 & YLYEIAR & PC(Y)@1 & & 18.5 & 2 & 546.80 & 546.78 & 0.02 & 1091.54 \\
\hline 7 & 0.2 & CCTESLVNR & $\begin{array}{l}\operatorname{Cam}(\mathrm{C}) @ 1 \\
\operatorname{Cam}(\mathrm{C}) @ 2 \\
\mathrm{PC}(\mathrm{T}) @ 3\end{array}$ & & 11.1 & 2 & 652.26 & 652.28 & 0.02 & 1302.55 \\
\hline 8 & 0.2 & RKVPQVSTPTLVEVSR & PC(K)@2 & cleaved T-R@N-term & 13.3 & 3 & 654.02 & 654.37 & 0.35 & 1960.09 \\
\hline
\end{tabular}

${ }^{1}$ Confidence score allocated by the Paragon algorithm in the ProteinPilot software.

${ }^{2}$ Variable modifications abbreviated as PC (phosphorylcholine), Cam (carbamidomethyl).

(a) Total Ion Chromatogram

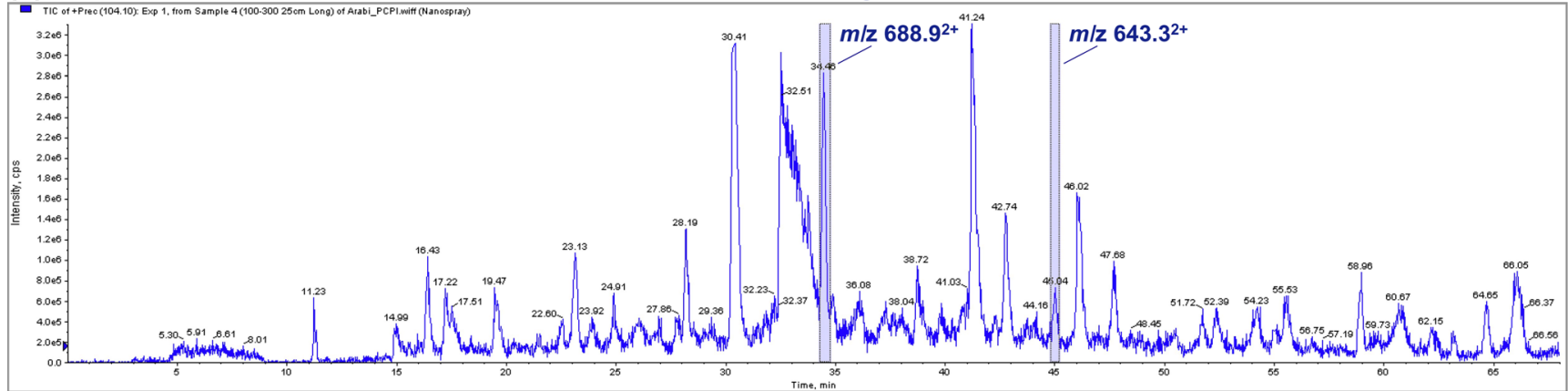

(b) MIDAS $\mathrm{m} / \mathrm{z} 688.9^{2+}$

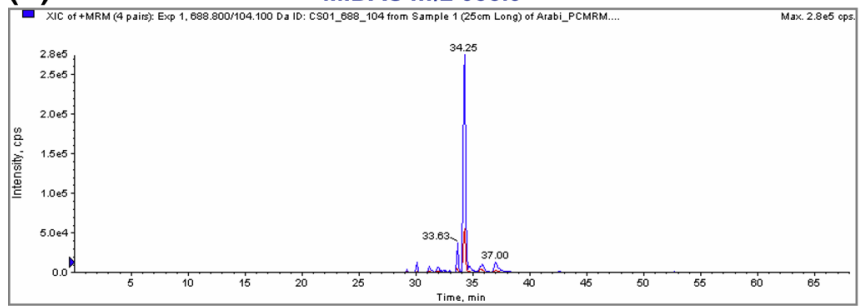

(d) MS/MS m/z 688.92+ identified as PVQNpc*KFFGLA

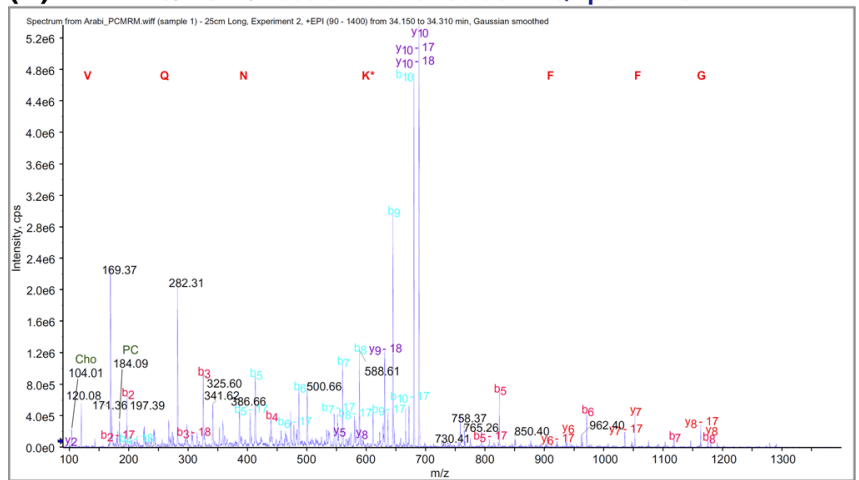

(c)

MIDAS $\mathrm{m} / \mathrm{z} 643.3^{2+}$

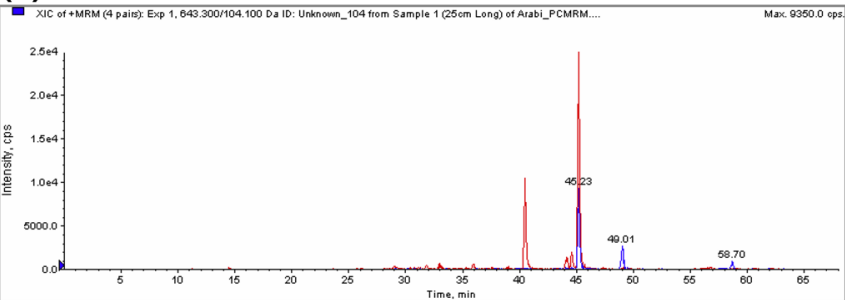

(e)

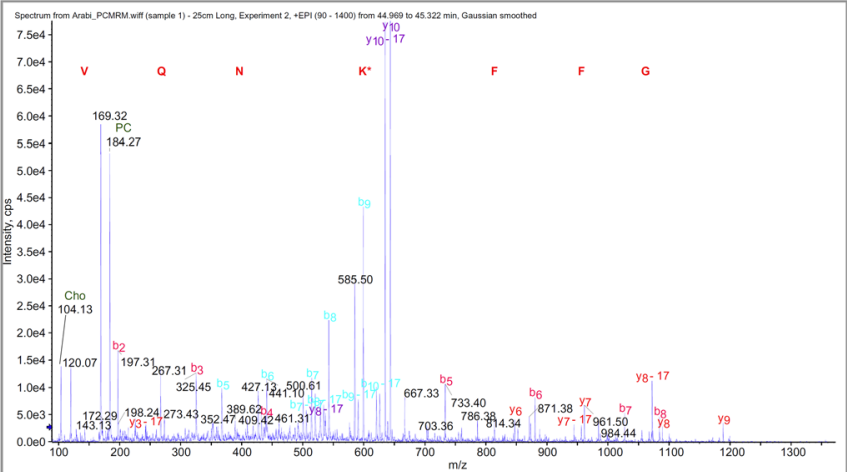

Figure 6. Detection of PC-substituted peptides in a complete tryptic digest of Arabidopsis thaliana and localization of the PCmodification within the peptide sequence by MS/MS. (a) Total ion chromatogram of a tryptic digest of $A$. thaliana with the two PCpeptides spiked in. By MRM of the two indicative ions for choline $(\mathrm{m} / \mathrm{z} 104.1)$ and phosphorylcholine $(\mathrm{m} / \mathrm{z}$ 184.1) both peptides could be detected (shaded areas at 34.46 and $45.04 \mathrm{~min}$ ); (b) and (c) MIDAS-profiles for the precursor fragment ions of 104.1 (blue) and 184.1 (red); (d) and (e) MS/MS-spectra of the PC-modified peptides. The spectra are characterized by strong fragment ion signals of the $b$ - and $y$-series, both found as single and double charged ions and the marker ions $\mathrm{m} / \mathrm{z} 104.1$ and 184.1. Assigned fragment ions are shown in the following colors: $b^{+}$: magenta, $y^{+}$: red, $b^{2+}$ : cyan, and $\mathrm{y}^{2+}$ : purple. The fragmentation patterns allowed an unambiguous localization of the PC-modification within the amino acid sequences 
553.31, and 938.57 Da, respectively) in case of CS-01-PC* (Figure 6d), and the b4 and y5 ions $(\mathrm{m} / \mathrm{z} 439.23$, and 733.47 Da, respectively) in case of CS-01-PC (Figure 6e). For the double-charged fragment-ions, numerous additional signals resulting from the loss of ammonia $(-17 \mathrm{Da})$ could be observed (for clearer arrangement not annotated in Figure 6). Interestingly, no signals originating from the neutral loss of choline or the complete phosphorylcholine moiety, i.e., $[\mathrm{M}+\mathrm{H}-103]^{+}$ (loss of choline) and $[\mathrm{M}+\mathrm{H}-183]^{+}$(loss of phosphorylcholine), or $[\mathrm{M}+\mathrm{H}-59]^{+}$(Hoffmann elimination of trimethylamine) could be observed. This is consistent with the fragmentation behavior observed for the PC-BSA peptides, where $\mathrm{N}$-derivatized peptides also produced predominantly sequence-specific fragments, whereas the spectra of Oderivatized peptides exhibited significant production of the $[\mathrm{M}+\mathrm{H}-103]+$ and $[\mathrm{M}+\mathrm{H}-183]+$ fragments, indicating a higher stability of the phosphoamidate bond under these conditions (compare Figure 5b-d).

\section{Conclusion}

Using a hybrid triple quadrupole/linear ion trap mass spectrometer, we have developed a LC/MS/MS workflow that allowed for the first time a sensitive and selective detection of PCmodified peptides within complex proteolytic digests. Precursor ion scanning and MRM of marker fragments $m / z 104.1$ and 184.1 were used to trigger collision cell CID fragmentations of modified peptides, allowing the identification of the peptide backbone and the localization of the PC-substituent. The transfer of the workflow from the QTRAP 4000 to the more sensitive QTRAP 4500 allowed us to detect and confirm PCmodified peptides even within a highly complex background of a tryptic digest from a complete organism. This methodological development is the prerequisite to head for the identification and structural determination of naturally occurring PCepitopes from parasites.

\section{Acknowledgments}

The authors thank Michael Dreisbach, Christina Schmidt, and Hans-Guenter Welker for excellent technical assistance. This work was supported by the German Research Council (SFB 535, TP Z1), the Rhön-Klinikums AG, and the LOEWE Research Focus "Non-neuronal cholinergic systems," an interdisciplinary collaborative research effort funded by the State of Hessen.

\section{References}

1. Lochnit, G., Dennis, R.D., Geyer, R.: Phosphorylcholine substituents in nematodes: structures, occurrence and biological implications. Biol. Chem. Hoppe. Seyler. 381, 839-847 (2000)

2. Harnett, W., Harnett, M.M.: Phosphorylcholine: friend or foe of the immune system? Immunol. Today. 20, 125-129 (1999)

3. Brundish, D.E., Baddiley, J.: Pneumococcal C-substance, a ribitol teichoic acid containing choline phosphate. Biochem. J. 110, 573 (1968)
4. Briles, E.B., Tomasz, A.: Pneumococcal Forssman antigen. A cholinecontaining lipoteichoic acid. J. Biol. Chem. 248, 6394-6397 (1973)

5. Weiser, J.N., Shchepetov, M., Chong, S.T.H.: Decoration of lipopolysaccharide with phosphorylcholine: a phase-variable characteristic of Haemophilus influenzae. Infect. Immun. 65, 943-950 (1997)

6. Houston, K.M., Harnett, W.: Attachment of phosphorylcholine to a nematode glycoprotein. Trends. Glycosci. Glycotechnol. 11, 43-52 (1999)

7. Lovell, T.M., Woods, R.J., Butlin, D.J., Brayley, K.J., Manyonda, I.T., Jarvis, J., Howell, S., Lowry, P.J.: Identification of a novel mammalian post-translational modification, phosphocholine, on placental secretory polypeptides. J. Mol. Endocrinol. 39, 189-198 (2007)

8. Lowry, P.: 1-O-alkenyl-sn-glyceryl-3-phosphorylcholine may be a novel posttranslational modification used by the placenta. Biopolymers. 96, 189192 (2011)

9. Harnett, W., Harnett, M.M.: Modulation of the host immune system by phosphorylcholine-containing glycoproteins secreted by parasitic filarial nematodes. Biochim. Biophys. Acta. 1539, 7-15 (2001)

10. Goodridge, H.S., Harnett, W., Liew, F.Y., Harnett, M.M.: Differential regulation of interleukin-12 p40 and p35 induction via Erk mitogenactivated protein kinase-dependent and -independent mechanisms and the implications for bioactive IL-12 and IL-23 responses. Immunology. 109, 415-425 (2003)

11. Marshall, F.A., Grierson, A.M., Garside, P., Harnett, W., Harnett, M.M.: ES-62, an immunomodulator secreted by filarial nematodes, suppresses clonal expansion and modifies effector function of heterologous antigenspecific T cells in vivo. J. Immunol. 175, 5817-5826 (2005)

12. Goodridge, H.S., Marshall, F.A., Else, K.J., Houston, K.M., Egan, C., AlRiyami, L., Liew, F.Y., Harnett, W., Harnett, M.M.: Immunomodulation via novel use of TLR4 by the filarial nematode phosphorylcholinecontaining secreted product, ES-62. J. Immunol. 174, 284-293 (2005)

13. Goodridge, H.S., Marshall, F.A., Wilson, E.H., Houston, K.M., Liew, F.Y., Harnett, M.M., Harnett, W.: In vivo exposure of murine dendritic cell and macrophage bone marrow progenitors to the phosphorylcholine-containing filarial nematode glycoprotein ES-62 polarizes their differentiation to an anti-inflammatory phenotype. Immunology. 113, 491-498 (2004)

14. Goodridge, H.S., Stepek, G., Harnett, W., Harnett, M.M.: Signaling mechanisms underlying subversion of the immune response by the filarial nematode secreted product ES-62. Immunology. 115, 296-304 (2005)

15. Melendez, A.J., Harnett, M.M., Pushparaj, P.N., Wong, W.F., Tay, H.K., McSharry, C.P., Harnett, W.: Inhibition of FceRI-mediated mast cell responses by ES-62, a product of parasitic filarial nematodes. Nat. Med. 13, 1375-1381 (2007)

16. Grabitzki, J., Lochnit, G.: Immunomodulation by phosphocholine-biosynthesis, structures, and immunological implications of parasitic PC-epitopes. Mol. Immunol. 47, 149-163 (2009)

17. Cipollo, J.F., Awad, A., Costello, C.E., Robbins, P.W., Hirschberg, C.B.: Biosynthesis in vitro of Caenorhabditis elegans phosphorylcholine oligosaccharides. Proc. Natl. Acad. Sci. U.S.A. 101, 3404-3408 (2004)

18. Cipollo, J.F., Awad, A.M., Costello, C.E., Hirschberg, C.B.: N-glycans of Caenorhabditis elegans are specific to developmental stages. J. Biol. Chem. 280, 26063-26072 (2005)

19. Lochnit, G., Bongaarts, R., Geyer, R.: Searching new targets for anthelminthic strategies: interference with glycosphingolipid biosynthesis and phosphorylcholine metabolism affects development of Caenorhabditis elegans. Int. J. Parasitol. 35, 911-923 (2005)

20. Gerdt, S., Dennis, R.D., Borgonie, G., Schnabel, R., Geyer, R.: Isolation, characterization, and immunolocalization of phosphocholine-substituted glycolipids in developmental stages of Caenorhabditis elegans. Eur. J. Biochem. 266, 952-963 (1999)

21. Wuhrer, M., Rickhoff, S., Dennis, R.D., Lochnit, G., Soboslay, P.T., Baumeister, S., Geyer, R.: Phosphocholine-containing, zwitterionic glycosphingolipids of adult Onchocerca volvulus as highly conserved, antigenic structures of parasitic nematodes. Biochem. J. 348, 417-423 (2000)

22. Lochnit, G., Dennis, R.D., Ulmer, A.J., Geyer, R.: Structural elucidation and monokine-inducing activity of two biologically active zwitterionic glycosphingolipids derived from the porcine parasitic nematode Ascaris suum. J. Biol. Chem. 278, 466-474 (1998)

23. Friedl, C.H., Lochnit, G., Zähringer, U., Bahr, U., Geyer, R.: Structural elucidation of zwitterionic carbohydrates derived from glycosphingolipids of the porcine parasitic nematode Ascaris suum. Biochem. J. 369, 89-102 (2003)

24. Friedl, C.H., Lochnit, G., Geyer, R., Karas, M., Bahr, U.: Structural elucidation of zwitterionic sugar cores from glycosphingolipids by 
nanoelectrospray ionization-ion-trap mass spectrometry. Anal. Biochem. 284, 279-287 (2000)

25. McClellan, J.E., Quarmby, S.T., Yost, R.A.: Parent and neutral loss monitoring on a quadrupole ion trap mass spectrometer: screening of acylcarnitines in complex mixtures. Anal. Chem. 74, 5799-5806 (2002)

26. Zhang, K., Yau, P.M., Chandrasekhar, B., New, R., Kondrat, R., Imai, B.S., Bradbury, M.E.: Differentiation between peptides containing acetylated or tri-methylated lysines by mass spectrometry: an application for determining lysine 9 acetylation and methylation of histone H3. Proteomics. 4, 1-10 (2004)

27. Pery, P., Petit, A., Poulain, J., Luffau, G.: Phosphorylcholine-bearing components in homogenates of nematodes. Eur. J. Immunol. 4, 637-639 (1974)

28. Maizels, R.M., Burke, J., Denham, D.A.: Phosphorylcholine-bearing antigens in filarial nematode parasites: analysis of somatic extracts, in-vitro secretions and infection sera from Brugia malayi and B. pahangi. Parasite. Immunol. 9, 49-66 (1987)

29. Wenger, J.D., Forsyth, K.P., Kazura, J.W.: Identification of phosphorylcholine epitope-containing antigens in Brugia malayi and relation of serum epitope levels to infection status of birds with Brugian filariasis. Am. J. Trop. Med. Hyg. 38, 133-141 (1988)

30. Lal, R.B., Ottesen, E.A.: Phosphocholine epitopes on helminth and protozoal parasites and their presence in the circulation of infected human patients. Trans. R. Soc. Trop. Med. Hyg. 83, 652-655 (1989)

31. Nor, Z.M., Houston, K.M., Devaney, E., Harnett, W.: Variation in the nature of attachment of phosphorylcholine to excretory-secretory products of adult Brugia pahangi. Parasitology. 114, 257-262 (1997)

32. Morelle, W., Haslam, S.M., Olivier, V., Appleton, J.A., Morris, H.R., Dell, A.: Phosphorylcholine-containing $N$-glycans of Trichinella spiralis: identification of multiantennary lacdiNAc structures. Glycobiology. 10, 941$950(2000)$

33. Haslam, S.M., Houston, K.M., Harnett, W., Reason, A.J., Morris, H.R., Dell, A.: Conservation of phosphorylcholine-substituted glycans among species and discovery of novel chito-oligomers. J. Biol. Chem. 274, 20953-20960 (1999)

34. Cipollo, J.F., Costello, C.E., Hirschberg, C.B.: The fine structure of Caenorhabditis elegans N-glycans. J. Biol. Chem. 277, 49143-49157 (2002)

35. Haslam, S.M., Gems, D., Morris, H.R., Dell, A.: The glycomes of Caenorhabditis elegans and other model organisms. Biochem. Soc. Symp. 69, 117-134 (2002)

36. Haslam, S.M., Khoo, K.H., Houston, K.M., Harnett, W., Morris, H.R., Dell, A.: Characterisation of the phosphorylcholine-containing $N$-linked oligosaccharides in the excretory-secretory $62 \mathrm{kDa}$ glycoprotein of Acanthocheilonema viteae. Mol. Biochem. Parasitol. 85, 53-66 (1997)

37. Lochnit, G., Grabitzki, J., Henkel, B., Tavernarakis, N., Geyer, R.: First identification of a phosphorylcholine-substituted protein from Caenorhabditis elegans: isolation and characterization of the aspartyl protease ASP-6. Biol. Chem. 387, 1487-1493 (2006)

38. Pöltl, G., Kerner, D., Paschinger, K., Wilson, I.B.: N-Glycans of the porcine nematode parasite Ascaris suum are modified with phosphorylcholine and core fucose residues. FEBS. J. 274, 714-726 (2007)
39. Hanneman, A.J., Rosa, J.C., Ashline, D., Reinhold, V.N.: Isomer and glycomer complexities of core GlcNAcs in Caenorhabditis elegans. Glycobiology. 16, 874-890 (2006)

40. Kooyman, F.N., van Balkom, B.W., de Vries, E., van Putten, J.P.: Identification of a thrombospondin-like immunodominant and phosphorylcholine-containing glycoprotein (GP300) in Dictyocaulus viviparus and related nematodes. Mol. Biochem. Parasitol. 163, 85-94 (2009)

41. Paschinger, K., Gonzalez-Sapienza, G.G., Wilson, I.B.: Mass spectrometric analysis of the immunodominant glycan epitope of Echinococcus granulosus antigen Ag5. Int. J. Parasitol. 42, 279-285 (2012)

42. Hegge, F.T., Hitchen, P.G., Aas, F.E., Kristiansen, H., Lovold, C., EggeJacobsen, W., Panico, M., Leong, W.Y., Bull, V., Virji, M., Morris, H.R., Dell, A., Koomey, M.: Unique modifications with phosphocholine and phosphoethanolamine define alternate antigenic forms of Neisseria gonorrhoeae type IV pili. Proc. Natl. Acad. Sci. U.S.A. 101, 10798$10803(2004)$

43. Grabitzki, J., Sauerland, V., Geyer, R., Lochnit, G.: Identification of phosphorylcholine substituted peptides by their characteristic mass spectrometric fragmentation. Eur. J. Mass. Spectr. 11, 335-344 (2005)

44. Rasmussen, S.E.: Covalent immobilization of biomolecules onto polystyrene microwells for use in biospecific assays. Ann. Biol. Clin. 48, 647-650 (1990)

45. Baltar, P., Romaris, F., Estevez, J., Leiro, J., Ubeira, F.M.: Carrierdependent suppression of the anti-phosphorylcholine plaque-forming cell response in Trichinella-infected mice is mediated by anti- hapten IgG1 antibodies. Exp. Parasitol. 90, 95-102 (1998)

46. Mohr, F., Zimmermann, M., Klein, J.: Mice heterozygous for AChE are more sensitive to $\mathrm{AChE}$ inhibitors but do not respond to $\mathrm{BuChE}$ inhibition. Neuropharmacology. 67, 37-45 (2013)

47. Bennett, K.L., Stensballe, A., Podtelejnikov, A.V., Moniatte, M., Jensen, O.N.: Phosphopeptide detection and sequencing by matrix-assisted laser desorption/ionization quadrupole time-of-flight tandem mass spectrometry. J. Mass. Spectrom. 37, 179-190 (2002)

48. Unwin, R.D., Griffiths, J.R., Leverentz, M.K., Grallert, A., Hagan, I.M., Whetton, A.D.: Multiple reaction monitoring to identify sites of protein phosphorylation with high sensitivity. Mol. Cell. Proteomics. 4, 1134-1144 (2005)

49. Cox, D.M., Zhong, F., Du, M., Duchoslav, E., Sakuma, T., McDermott, J.C.: Multiple reaction monitoring as a method for identifying protein posttranslational modifications. J. Biomol. Tech. 16, 83-90 (2005)

50. Mollah, S., Wertz, I.E., Phung, Q., Arnott, D., Dixit, V.M., Lill, J.R.: Targeted mass spectrometric strategy for global mapping of ubiquitination on proteins. Rapid. Commun. Mass. Spectrom. 21, 3357-3364 (2007)

51. Evans, C.A., Griffiths, J.R., Unwin, R.D., Whetton, A.D., Corfe, B.M.: Application of the MIDAS approach for analysis of lysine acetylation sites. Methods. Mol. Biol. 981, 25-36 (2013)

52. Lenz, C., Kühn-Hölsken, E., Urlaub, H.: Detection of protein-RNA crosslinks by NanoLC-ESI-MS/MS using precursor ion scanning and multiple reaction monitoring (MRM) experiments. J. Am. Soc. Mass. Spectrom. 18, 869-881 (2007) 